\title{
Adiponectin Paradox as a Therapeutic Target in Alzheimer's Disease
}

\author{
Masaaki Waragai $^{\mathrm{a}}$, Gilbert Ho ${ }^{\mathrm{b}}$, Yoshiki Takamatsu ${ }^{\mathrm{a}}$, Ryoko Wada ${ }^{\mathrm{a}}$, Shuei Sugama ${ }^{\mathrm{c}}$, \\ Takato Takenouchi ${ }^{\mathrm{d}}$, Eliezer Masliah $^{\mathrm{e}}$ and Makoto Hashimoto ${ }^{\mathrm{a}, *}$ \\ ${ }^{a}$ Tokyo Metropolitan Institute of Medical Science, Setagaya-ku, Tokyo, Japan \\ ${ }^{\mathrm{b}}$ PCND Neuroscience Research Institute, Poway, CA, USA \\ ${ }^{\mathrm{c}}$ Department of Physiology, Nippon Medical School, Tokyo, Japan \\ ${ }^{\mathrm{d}}$ Institute of Agrobiological Sciences, National Agriculture and Food Research Organization, \\ Tsukuba, Ibaraki, Japan \\ ${ }^{\mathrm{e}}$ Division of Neurosciences, National Institute on Aging, National Institutes of Health, Bethesda, MD, USA
}

Accepted 1 June 2020

\begin{abstract}
Despite the apparent neurotoxicity of amyloid- $\beta(A \beta)$, recent clinical trials of $A \beta$ immunotherapy have not shown any clinical benefit in Alzheimer's disease (AD). Given this, clarification of the next generation therapeutic strategy in AD is warranted. Hypothetically, adiponectin might be involved in promoting amyloidogenic evolvability in reproduction, which may result in the adiponectin paradox through antagonistic pleiotropy mechanism in aging, leading to AD. Accordingly, preventing the adiponectin paradox by suppressing adiponectin signaling might prove therapeutic in AD.
\end{abstract}

Keywords: A $\beta$ immunotherapy, adiponectin, adiponectin paradox, Alzheimer's disease, amyloid- $\beta$, amyloidogenic evolvability, antagonistic pleiotropy

Although the amyloid cascade hypothesis $(\mathrm{ACH})$ has placed amyloid- $\beta(\mathrm{A} \beta)$ at the center of Alzheimer's disease $(\mathrm{AD})$ pathogenesis, recent clinical trials of $\mathrm{A} \beta$ immunotherapy in $\mathrm{AD}$ have been unsuccessful, casting doubt on the ACH [1]. Initial human trial of $A \beta$ immunotherapy used active immunization of recombinant $A \beta_{42}$, but the trial was suspended due to side effects such as encephalomyelitis [2]. Although histological analysis of autopsy brains from $A \beta$ immunized patients were free from $A \beta$ pathology [3, 4], no symptomatic improvement in dementia was observed.

\footnotetext{
*Correspondence to: Makoto Hashimoto, Tokyo Metropolitan Institute of Medical Science, 2-1-6 Kamikitazawa, Setagaya-ku, Tokyo 156-0057, Japan. Tel.: +81 36834 2354; Fax: +81 35316 3150; E-mail: hashimoto-mk@igakuken.or.jp.
}

Subsequently, several passive A $\beta$ immunotherapies using either monoclonal or polyclonal $A \beta$ anti bodies were tested in humans, also without success [5]. As a group, $A \beta$ immunotherapy has largely not demonstrated efficacy, and one possible rationale for such failure was that timing of the treatment intervention was too late in the disease course. Accordingly, passive $A \beta$ immunotherapies were initiated from the asymptomatic early stage of dominantly inherited $\mathrm{AD}$ [6]. An exception, aducanumab, resulting from a collaborative effort between Eisai and Biogen, although controversial, is still under consideration by the US Food and Drug Administration for potential approval [7]. Yet, two other monoclonal antibody therapies, gantenerumab and solanezumab, developed by Roche and Eli Lilly respectively, had failed to improve cognition in Phase II/III trials [8, 9]. 
Based on the dissociation of protein aggregation of $A \beta$ from cognitive deficits [10], it was predicted that tau, another pathological hallmark of $\mathrm{AD}$, might be a candidate as the next therapeutic target of AD [11], since tau has been implicated in the synaptic pathology and cognitive dysfunction [12]. Consistently, it was recently described that specific phosphorylation sites of tau were associated with structural, metabolic, neurodegenerative and clinical markers of AD [13, 14]. Currently, a phase II clinical study of tau immunotherapy in $\mathrm{AD}$ is in progress, including both active and passive immunotherapy $[15,16]$. The basic idea of tau as a therapeutic target, however, remains similar to the $\mathrm{ACH}$ in that both are based on the pathological functions of amyloidogenic proteins (APs).

In addition, a better understanding of the physiological function of $A \beta$ might be necessary for successful therapy development in AD. As such, we recently proposed that evolvability might be a physiological function of APs relevant to neurodegenerative diseases, such as $\mathrm{A} \beta$ in $\mathrm{AD}$ and $\alpha$-synuclein in Parkinson's disease [17, 18]. Evolvability is the ability of a population of organisms to not merely generate genetic diversity, but to generate adaptive genetic diversity, and thereby evolve through natural selection [19]. Namely, evolvability is defined as the capacity of a system for adaptive evolution [19]. More specifically, the diverse $\beta$-sheet structures of protofibrillar APs forms that are found within the intrinsically disordered structures might confer resistance against multiple stressors in parental brains. Subsequently, the protofibrillar APs may be transmitted to offspring through germ cells in a prion-like manner $[17,18,20]$. By virtue of the stress information of APs derived from parental brains, an off spring's brain can better cope with forthcoming stresses to avoid developmental disorders. On the other hand, neurodegeneration may manifest in parental brains through the antagonistic pleiotropy mechanism in aging. Hereafter, we refer to our view as the evolvability hypothesis (EVH). If EVH is validated, it is expected that EVH might provide clues for AD therapy.

Since recent evidence suggests that the adiponectin paradox might be involved in the pathogenesis of AD [20], we speculated that this phenomenon might be relevant to evolvability. Adiponectin is a cytokine produced by adipocytes that is involved in regulation of energy balance and metabolism as well as other multiple functions, including sensitization of insulin receptor signaling, stimulation of mitochondria biogenesis, and suppression of inflammation [21]. Not withstanding the protective property of adiponectin in many experimental systems, adiponectin is detrimental in aging-associated circulatory diseases, including chronic heart failure and chronic kidney disease, the so-called APN paradox [20]. In the nervous system, adiponectinis protective against neurotoxicity caused by MPP+ (1-methyl-4-phenyl-pyridinium) and $\mathrm{A} \beta$ in vitro, and kainic acid-induced excitotoxicity in vivo [21]. Consistent with these findings, adiponectin has been shown to be anti-neurodegenerative in mouse models. For instance, adiponectin was protective against $\alpha$-synuclein-induced neurodegeneration [22]. Furthermore, osmosin, a plant homologue of adiponectin, was protective against $A \beta$ toxicity [23]. Moreover, knockout of a gene for adiponectin receptor in mice resulted in neurodegeneration [24].

Despite these beneficial properties of adiponectin, adiponectin might also be detrimental in the brain. Supporting this, a recent prospective cohort study in elderly showed that serum adiponectin levels were associated with the severity of amyloid deposits and cognitive deficits, suggesting that adiponectin might stimulate formation of $\mathrm{A} \beta$ amyloidosis in the elderly [25]. Moreover, serum adiponectin levels were associated with worse cognitive function in postmenopausal women, which was recently confirmed in another study [26, 27]. On the other hand, increased levels of serum adiponectin were independently reported in $\mathrm{AD}$ [21]. Meanwhile, histopathological studies of the postmortem AD brains revealed that adiponectin was sequestered by phospho-tau into the neurofibrillary tangle, implying that tau aggregation was stimulated by adiponectin [28]. Collectively, adiponectin is neuroprotective and anti-neurodegenerative in reproduction, but may promote $\mathrm{AD}$ in aging, otherwise known as the adiponectin paradox in $\mathrm{AD}$ [20]. We predict that the adiponectin paradox in $\mathrm{AD}$ might be derived from the stimulatory effect of adiponectin on amyloidogenic evolvability in reproduction through antagonistic pleiotropy mechanism (Fig. 1). Given that the effect of adiponectin on evolvability in reproduction is beneficial for offspring, adiponectin paradox, the detrimental phenomenon in aging, persists against the pressure of natural selection in evolution.

At present, the precise mechanism of the adiponectin paradox in $\mathrm{AD}$ remains obscure. Because aging-associated circulatory diseases, such as chronic heart failure and chronic kidney disease, are associated with adiponectin paradox [20], in which 


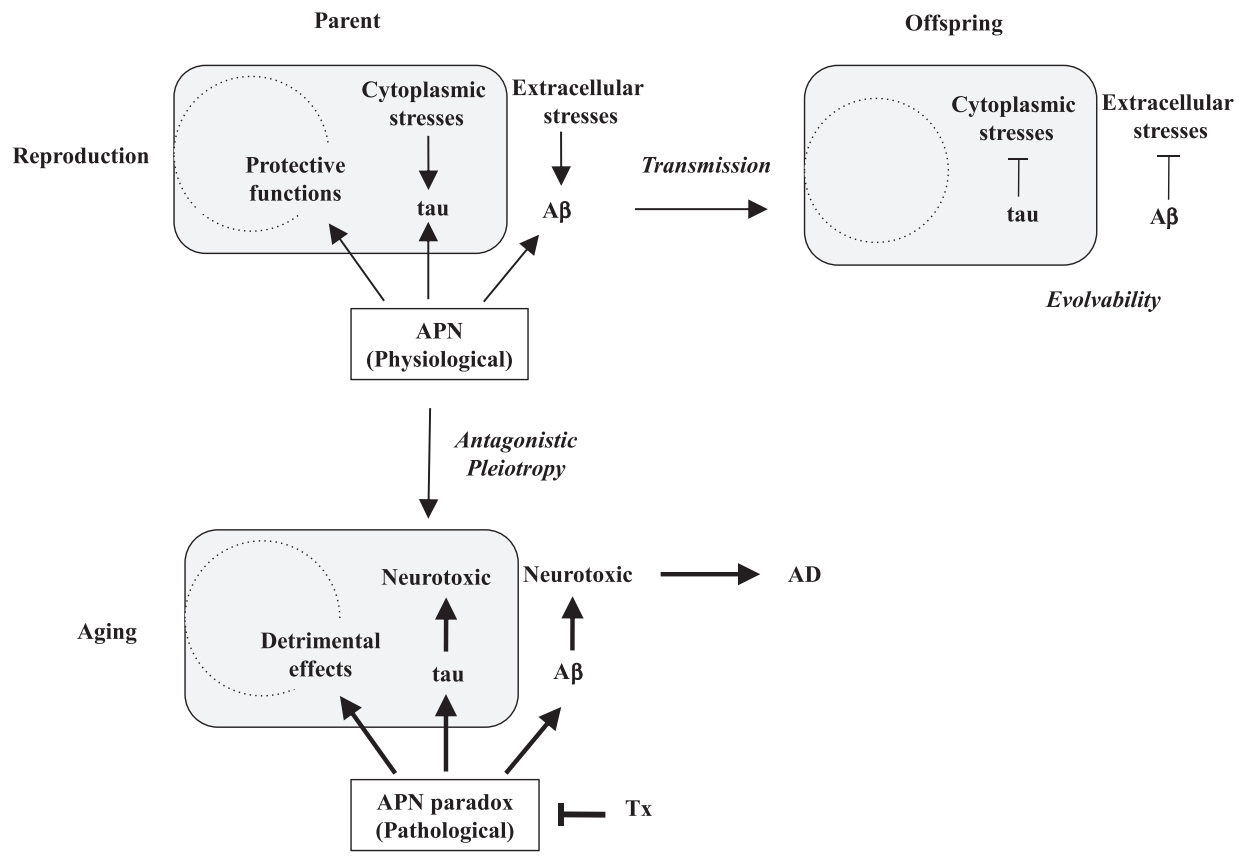

Fig. 1. Schematic of the APN regulation of amyloiogenic evolvability and AD. According to EVH, A $\beta$ is involved in evolvability against stressors in the extracellular spaces, while tau is against the stressors in the cytoplasm in parental brain. In response to multiple stressors, aggregation of APs, including A $\beta$ and tau, is induced, and the resulting protofibrils of APs might confer the stress resistance. Subsequently, the APs protofibrils might be transmitted to off spring via germ cells. By virtue of the information carried by the transmission of APs protofibrils in reproduction, off spring can cope with the forth-coming stresses in the brain to escape from neurodevelopmental diseases. Thus, the APs protofibrils might be involved in evolvability against stressors in brain, which is evolutionally beneficial. However, the evolvability of APs protofibrils may increase the risk of AD through the antagonistic pleiotropy in aging. APN may be neuroprotective and stimulate evolvability by the APs protofibrils in reproduction. However, APN might stimulate the development of AD in aging, namely APN paradox. Therefore, decrease of APN expression could be therapeutic (Tx).

adiponectin resistance may be multi factorial, integrating abnormalities emanating from insulin signaling, mitochondrial biogenesis, and ceramide metabolism [29], a similar mechanism might be applied to the adiponectin paradox in $\mathrm{AD}$. We predict, however, that adiponectin resistance in evolvability might be a physiological phenomenon, which is distinct from adiponectin resistance in the pathogenesis of AD. Notably, insulin resistance is physiologically important to protect cardiovascular tissues from nutrient-induced injury [30]. Thus, both adiponectinand insulin resistance might be able to act as adaptive defense mechanisms. Increased levels of adiponectin due to adiponectin resistance may result in more frequent interaction with APs, leading to neurodegeneration in AD. Further supporting the notion of the role for adiponectin in promoting $\mathrm{AD}$, it was established that mid-life obesity is an established risk factor for $\mathrm{AD}$, whereas late-life obesity has been proposed as a protective state [31]. Since expression of adiponectin is down regulated in obesity, the adiponectin paradox and the obesity paradox in $\mathrm{AD}$ risk might appear contradictory, but could in fact, represent the same phenomenon.

Given that adiponectin increases protein aggregation and cognitive deficits in the adiponectin paradox, leading to $\mathrm{AD}$, it is reasonable to predict that the adiponectin signaling might be a therapeutic target (Fig. 1). At the ligand level, dose-reduction of adiponectin might be considered. For this purpose, antisense oligonucleotide strategy could be used to reduce the adiponectin mRNA [32], or immunotherapy could suppress adiponectin protein expression. At the receptor level, antagonist-mediated inhibition of adiponectin receptor signaling pathway might also be effective. Antagonists could be designed by molecular docking methods as previously described [33].

Although adiponectin might be promising as a next generation target for AD therapy, there are many issues to be unraveled. In particular, it should be recognized that the effects of adiponectin depend on the stage of AD. In early stages, adiponectin might be neuroprotective with multiple beneficial functions, while adiponectin might be detrimental, promoting 
the adiponectin paradox in later disease stages. Therefore, it is important to examine whether decreased adiponectin might turn out to be a "trade off." Conversely, adiponectin might be used as a biomarker to assess the stage of $\mathrm{AD}$. Thus, further investigations are warranted for these issues.

In summary, adiponectin might serve as a driving force of $\mathrm{AD}$, and suppression of the adiponectin paradox might be therapeutic for AD. Thus, a better understanding of the role of adiponectin in evolvability in reproduction and neurodegeneration in aging may pave a new avenue for the therapy of AD.

\section{ACKNOWLEDGMENTS}

We are grateful for the continuous encouragement of Drs. Kaori Hashimoto (Tokyo Metropolitan Institute of Medical Science) and Maria del Carmen Ruiz de la Cruz (University of Chicago). This paper is supported by neither public nor private grants.

Authors' disclosures available online (https:// www.j-alz.com/manuscript-disclosures/20-0416r1).

\section{REFERENCES}

[1] Tolar M, Abushakra S, Sabbagh M (2020) The path forward in Alzheimer's disease therapeutics: Reevaluating the amyloid cascade hypothesis. Alzheimers Dement, doi: 10.1016/j.jalz.2019.09.075

[2] Orgogozo JM, Gilman S, Dartigues JF, Laurent B, Puel M, Kirby LC, Jouanny P, Dubois B, Eisner L, Flitman S, Michel BF, Boada M, Frank A, Hock C (2003) Subacute meningoencephalitis in a subset of patients with AD after Abeta42 immunization. Neurology 61, 46-54.

[3] Serrano-Pozo A, William CM, Ferrer I, Uro-Coste E, Delisle MB, Maurage CA, Hock C, Nitsch RM, Masliah E, Growdon JH, Frosch MP, Hyman BT (2010) Beneficial effect of human anti-amyloid-beta active immunization on neurite morphology and tau pathology. Brain 133, 1312-1327.

[4] Holmes C, Boche D, Wilkinson D, Yadegarfar G, Hopkins V, Bayer A, Jones RW, Bullock R, Love S, Neal JW, Zotova E, Nicoll JA (2008) Long-term effects of Abeta42 immunisation in Alzheimer's disease: Follow-up of a randomised, placebo-controlled phase I trial. Lancet 372, 216-223.

[5] Takamatasu YHG, Koike W, Sugama S, Takenouchi T, Waragai M, Wei J, Sekiyama K, Hashimoto M (2017) Combined immunotherapy with "anti-insulin resistance" therapy as a novel therapeutic strategy against neurodegenerative diseases. NPJ Parkinsons Dis 3, 4.

[6] Moulder KL, Snider BJ, Mills SL, Buckles VD, Santacruz AM, Bateman RJ, Morris JC (2013) Dominantly Inherited Alzheimer Network: Facilitating research and clinical trials. Alzheimers Res Ther 5, 48.

[7] Schneider L (2020) A resurrection of aducanumab for Alzheimer's disease. Lancet Neurol 19, 111-112.

[8] Roche (2020) Roche provides topline results from investigator-led phase $2 / 3$ trial with ganterenumab in rare inherited form of Alzheimer disease [news release]. https://www.roche.com/media/releases/med-cor2020-02-10.htm

[9] Eli Lilly and Company (2020) Lilly announces topline results for solanezumab from the dominantly inherited Alzheimer Network Trials Unit (DIAN-TU) study [news release]. https://www.prnewswire.com/news-releases/lillyannounces-topline-results-for-solanezumab-from-thedominantly-inherited-alzheimer-network-trials-unit-diantu-study-301001653.html

[10] Sekiyama K, Takamatsu Y, Koike W, Waragai M, Takenouchi T, Sugama S, Hashimoto M (2016) Insight into the dissociation of behavior from histology in synucleinopathies and in related neurodegenerative diseases. $J$ Alzheimers Dis 52, 831-841.

[11] Congdon EE, Sigurdsson EM (2018) Tau-targeting therapies for Alzheimer disease. Nat Rev Neurol 14, 399-415.

[12] Tracy TE, Gan L (2018) Tau-mediated synaptic and neuronal dysfunction in neurodegenerative disease. Curr Opin Neurobiol 51, 134-138.

[13] Thijssen EH, La Joie R, Wolf A, Strom A, Wang P, Iaccarino L, Bourakova V, Cobigo Y, Heuer H, Spina S, VandeVrede L, Chai X, Proctor NK, Airey DC, Shcherbinin S, Duggan Evans C, Sims JR, Zetterberg H, Blennow K, Karydas AM, Teunissen CE, Kramer JH, Grinberg LT, Seeley WW, Rosen H, Boeve BF, Miller BL, Rabinovici GD, Dage JL, Rojas JC, Boxer AL, Advancing Research and Treatment for Frontotemporal Lobar Degeneration (ARTFL) investigators (2020) Diagnostic value of plasma phosphorylated tau181 in Alzheimer's disease and frontotemporal lobar degeneration. Nat Med 26, 387-397.

[14] Barthelemy NR, Li Y, Joseph-Mathurin N, Gordon BA, Hassenstab J, Benzinger TLS, Buckles V, Fagan AM, Perrin RJ, Goate AM, Morris JC, Karch CM, Xiong C, Allegri R, Mendez PC, Berman SB, Ikeuchi T, Mori H, Shimada H, Shoji M, Suzuki K, Noble J, Farlow M, Chhatwal J, Graff-Radford NR, Salloway S, Schofield PR, Masters CL, Martins RN, O'Connor A, Fox NC, Levin J, Jucker M, Gabelle A, Lehmann S, Sato C, Bateman RJ, McDade E, Dominantly Inherited Alzheimer Network (2020) A soluble phosphorylated tau signature links tau, amyloid and the evolution of stages of dominantly inherited Alzheimer's disease. Nat Med 26, 398-407.

[15] Shahpasand K, Sepehri Shamloo A, Nabavi SM, Ping Lu K, Zhen Zhou X (2018) Tau immunotherapy: Hopes and hindrances. Hum Vaccin Immunother 14, 277-284.

[16] Novak P, Kontsekova E, Zilka N, Novak M (2018) Ten years of tau-targeted immunotherapy: The path walked and the roads ahead. Front Neurosci 12, 798.

[17] Hashimoto M, Ho G, Sugama S, Takamatsu Y, Shimizu Y, Takenouchi T, Waragai M, Masliah E (2018) Evolvability of amyloidogenic proteins in human brain. J Alzheimers Dis 62, 73-83.

[18] Hashimoto M, Ho G, Takamatsu Y, Shimizu Y, Sugama S, Takenouchi T, Waragai M, Masliah E (2018) Evolvability and neurodegenerative disease: Antagonistic pleiotropy phenomena derived from amyloid aggregates. J Parkinsons Dis 8, 405-408.

[19] Kirschner M, Gerhart J (1998) Evolvability. Proc Natl Acad Sci U S A 95, 8420-8427.

[20] Waragai M, Ho G, Takamatsu Y, Wada R, Sugama S, Takenouchi T, Masliah E, Hashimoto M (2020) Adiponectin paradox in Alzheimer's disease; relevance to amyloidogenic evolvability? Front Endocrinol (Lausanne) 11, 108.

[21] Waragai M, Ho G, Takamatsu Y, Sekiyama K, Sugama S, Takenouchi T, Masliah E, Hashimoto M (2017) Importance 
of adiponectin activity in the pathogenesis of Alzheimer's disease. Ann Clin Transl Neurol 4, 591-600.

[22] Sekiyama K, Waragai M, Akatsu H, Sugama S, Takenouchi T, Takamatsu Y, Fujita M, Sekigawa A, Rockenstein E, Inoue S, La Spada AR, Masliah E, Hashimoto M (2014) Disease-modifying effect of adiponectin in model of alphasynucleinopathies. Ann Clin Transl Neurol 1, 479-489.

[23] Ali T, Yoon GH, Shah SA, Lee HY, Kim MO (2015) Osmotin attenuates amyloid beta-induced memory impairment, tau phosphorylation and neurodegeneration in the mouse hippocampus. Sci Rep 5, 11708 .

[24] Ng RC, Cheng OY, Jian M, Kwan JS, Ho PW, Cheng KK, Yeung PK, Zhou LL, Hoo RL, Chung SK, Xu A, Lam KS, Chan KH (2016) Chronic adiponectin deficiency leads to Alzheimer's disease-like cognitive impairments and pathologies through AMPK inactivation and cerebral insulin resistance in aged mice. Mol Neurodegener 11, 71.

[25] Wennberg AM, Gustafson D, Hagen CE, Roberts RO, Knopman D, Jack C, Petersen RC, Mielke MM (2016) Serum adiponectin levels, neuroimaging, and cognition in the Mayo Clinic Study of Aging. J Alzheimers Dis 53, 573581.

[26] van Himbergen TM, Beiser AS, Ai M, Seshadri S, Otokozawa S, Au R, Thongtang N, Wolf PA, Schaefer EJ (2012) Biomarkers for insulin resistance and inflammation and the risk for all-cause dementia and Alzheimer disease: Results from the Framingham Heart Study. Arch Neurol 69, 594-600.

[27] De Franciscis P, Barbieri M, Leo S, Dalise AM, Sardu C, Marfella R, Colacurci N, Paolisso G, Rizzo MR (2017)
Serum adiponectin levels are associated with worse cognitive function in postmenopausal women. PLoS One 12, $\mathrm{e} 0186205$.

[28] Waragai M, Adame A, Trinh I, Sekiyama K, Takamatsu Y, Une K, Masliah E, Hashimoto M (2016) Possible involvement of adiponectin, the anti-diabetes molecule, in the pathogenesis of Alzheimer's disease. J Alzheimers Dis $\mathbf{5 2}$, 1453-1459.

[29] Sente T, Van Berendoncks AM, Hoymans VY, Vrints CJ (2016) Adiponectin resistance in skeletal muscle: Pathophysiological implications in chronic heart failure. $J$ Cachexia Sarcopenia Muscle 7, 261-274.

[30] Nolan CJ, Ruderman NB, Kahn SE, Pedersen O, Prentki M (2015) Insulin resistance as a physiological defense against metabolic stress: Implications for the management of subsets of type 2 diabetes. Diabetes 64, 673-686.

[31] Fitzpatrick AL, Kuller LH, Lopez OL, Diehr P, O’Meara ES, Longstreth WT, Jr., Luchsinger JA (2009) Midlife and late-life obesity and the risk of dementia: Cardiovascular health study. Arch Neurol 66, 336-342.

[32] Rinaldi C, Wood MJA (2018) Antisense oligonucleotides: The next frontier for treatment of neurological disorders. Nat Rev Neurol 14, 9-21.

[33] Waragai M, Ho G, Takamatsu Y, Shimizu Y, Sugino H, Sugama S, Takenouchi T, Masliah E, Hashimoto M (2018) Dual-therapy strategy for modification of adiponectin receptor signaling in aging-associated chronic diseases. Drug Discov Today 23, 1305-1311. 